\title{
Comparison of Environmental Benchmarks of Masonry and Concrete Structure Based on a Building Model
}

\author{
António José Morais
}

\begin{abstract}
Construction materials have distinguished energy consumptions and different emissions of carbon dioxide from fabrication up to application. The processes and the treatments needed to transform the raw materials into the final products, the transport to the construction sites and the techniques used for their application, all contribute to the differences in embodied energy and carbon footprint of these materials. In an environmental assessment one wonders what kind of constructive solution is environmentally more favorable. This study refers to the environmental comparison of reinforced concrete and ceramic bricks. Through a digital three-dimensional building model, the required data are analyzed. The building model is once considered with a reinforced concrete structure, consisting of columns, beams and slabs, with brick walls in between the columns in the periphery and interior of the building. Then, structural masonry with ceramic blocks in the exterior and interior walls is studied. Both models are analyzed in two versions. In the first version the slabs are of reinforced concrete and in the second version the slabs are built in pre stressed concrete beams and ceramic blocks. The building model represents for all solutions equal conditions. The comparison is limited to the quantification of the most important environmental parameters, the embodied energy and $\mathrm{CO} 2$ emissions. The results of this study show that the Masonry Model Version 1 has a $11 \%$ reduction in $\mathrm{CO} 2$ and $12 \%$ reduction in energy consumption, while Version 2 has a $39 \%$ reduction in $\mathrm{CO} 2$ and $41 \%$ reduction in energy consumption compared to the construction with reinforced concrete structure. These differences are due to the reduction of reinforced concrete in structural masonry, which is more significant for Version 2.
\end{abstract}

Keywords - masonry; carbon dioxide emissions; carbon footprint; embodied energy; environmental benchmarks.

\section{INTRODUCTION}

When intending to build a new building, more and more the question arises as to which materials to use. How one can contribute to protection of environment by reducing pollution and consumption of energy? Further research and useful results are needed in this field to make right decisions. Much has been done on the Life Cycle Assessment (LCA).

A LCA analyses the environmental impact of a product concerning various stages, it may evaluate a particular building examining from the manufacturing of the construction materials up to the period of operation including the construction of the building itself, the

António José Morais is Associate Professor, Faculty of Architecture, Director of the technology department, Lisbon University - FAUL, Portugal. architecture and the environmental impacts that influence the building. The LCA results, although very conclusive for that particular building, are for another building project at most a slight orientation, as the architecture, the geography and the environmental impact change. So far, the question of, which construction material has less embodied energy and gas emission is open. [1][2][3][4] A possible solution is the method of comparison according to the recommendations of ISO 14040, which establishes that to compare products functional units must be created. These functional units must be functional in the sense that the products to compare should perform the same function and operate under the same physical and environmental conditions. In this research a virtual building is considered as a functional unit. This building can be built with different materials and will be analyzed. The physical and environmental conditions depend on the objective of the study and have been accordingly adapted. Following this methodology, this study aims to compare the environmental performance of two common construction forms, i.e. reinforced concrete and brick masonry. For this purpose a digital three-dimensional building model is designed to enable the comparison according to ISO 14040. The conditions to create are the minimum necessary structure, to use the minimum of quantity of materials and to design similar thermal comfort in the virtual buildings to guarantee the same habitat quality. The comparison analyses the Embodied Energy and the Carbon Dioxide emissions from the production of the material until delivery at construction site and the energy needed for comparable thermal comfort. One model is constructed with a structure in reinforced concrete, columns, beams and slabs, with exterior and interior walls in bricks, which is designated as concrete

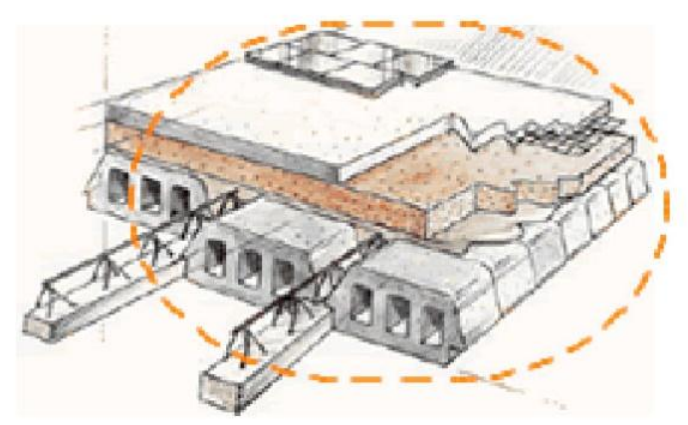

Fig. 1 Ceiling beam and block system

construction or Concrete Model CM; the other in non reinforced masonry, designated as Masonry Model MM. 
Both models are studied in two different versions; the first version has solid slabs of reinforced concrete and the second version has beam and block ceilings. Both masonry models are deliberately not reinforced, highlighting the advantages or disadvantages of using the ceramic material.

It has to be mentioned that this research is at this stage limited to the southern European regions regarding climate and earthquake activities for the materials used. Certainly, the research is applicable for other regions under same conditions. The following paragraphs explain the differences and how this research could be adopted for northern European countries. The proposed building model corresponds to the usual average dimensions of residential buildings. Since this study is dealing with masonry construction in an earthquake zone, the relationship of the geometry with the height of the building is of great importance and must be considered to fulfill applicable standards. On the other hand the model in concrete construction, has no limitations regarding the geometry of the building, its flexibility in structural stability is generally known. [5] Following the directives of the Eurocode (EC) 6, for masonry, EC 2, for reinforced concrete and EC 8 for earthquake design, the building models are designed to cover all stability requirements, guaranteeing equal minimum stability safety to keep the solutions comparable for the research. Furthermore the dimensions and spans of the model have to correspond to the usual medium sizes of the majority of constructed buildings to obtain results that will be of general interest. The general architectural ground plant for the models is presented in Figure 2 with a construction area of $167,6 \mathrm{~m} 2$. The reticulated concrete structure consisting of columns, beams and slabs in case of the Concrete Model aligns with the exterior walls and the three interior walls of the plant. In case of the Masonry Model the exterior and the three structural interior walls coincide with the walls presented in the plant. [5]

The key requirement for this study is the adequate collection of data regarding energy consumption and carbon dioxide emissions from the manufacturing of the construction materials chosen for the building models. In case of the masonry, the right choice of the brick that performs the necessary mechanical properties is of certain importance. To make the comparison more correct and the

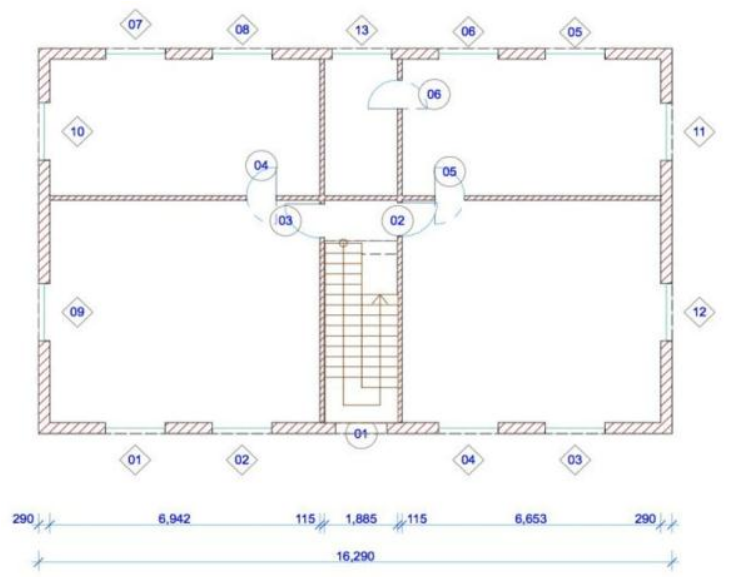

Fig. 2 Ground plan of the building model [5] results more clear, the landing slabs of the stairway of the building are supported on the exterior wall, which creates a structural disadvantage for the masonry and represents the worst scenario. This disadvantage consists of the probability of excess of eccentricity of the axial forces in the exterior wall that supports the stairway. The eccentricity is worsened through the variation of the ceiling heights along the exterior wall. This fact obliges to choose a wider brick that enables to support more efficiently the eccentricity of the axial forces. Consequently, this raises the weight of the bricks, which results in more energy consumption and gas emissions for masonry. Other relevant problems to consider in the choice of the materials for masonry are the low resistance against traction, especially in the joint section, the ductility and the bending of exterior walls. The selection of construction materials for the masonry model is very conditional. On the contrary for the Concrete Model, being free of these conditions, the selection is adapted to the masonry model to create two scientifically equal and comparable building models. Considering the thermal comfort for both models, which is the other condition to create for the correct comparison of the models, the objective is to reach similar average thermal conductivity for the exterior walls. The roof can be excluded, because the two versions are the same for both models, having the same thermal properties. For exterior walls an insulation of $3 \mathrm{~cm}$, with a thermal conductivity of $0,035 \mathrm{~W} / \mathrm{mK}$, applied in both models. This will result in a similar thermal transmittance of $0,456 \mathrm{~W} / \mathrm{m} 2 \mathrm{~K}$ for the Concrete Model and 0,422 W/m2K for the Masonry. To understand the difference in energy consumption for both models the energy consumption during operation of the models in the region of Cavado in the north of Portugal is considered and estimated in accordance with the Portuguese law, 118/2013 of 20th of August, "Regulation of Energy Performance of Residential Buildings". The CM consumes in 50 years 815,8752 and the MM 755,0424 KWh/m2. As both values are very close, this result proofs that in both models the thermal comfort quality is fairly similar. Hereby the necessary conditions are created and as the insulation is equal for both models the insulation needs not to be quantified. This has the advantage that the quantifications will concentrate on the materials that directly relate to the comparison and are not of secondary nature. Figures 3 and 4 show the structure of the exterior walls of the models.

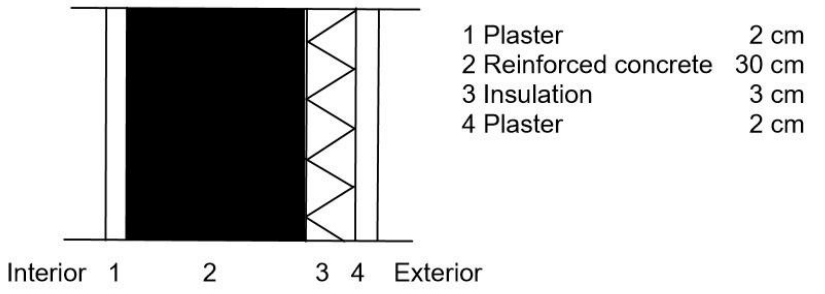

Fig. 3 Exterior wall of CM

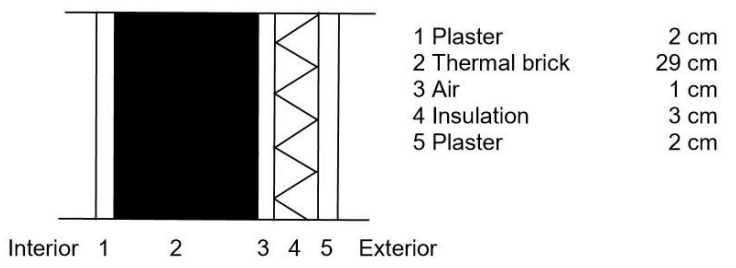

Fig. 4 Exterior wall of MM 


\section{THE BUILDING MODEL IN STRUCTURAL MASONRY}

The stability assessment detects geometry problems and enhances the development of more specific and adequate solutions. Various combinations of geometry, functions and height of the building are manually calculated to obtain a construction system with appropriate types of ceramic blocks considering the non-linear behavior of masonry, which is a combination of blocks and joints. As the masonry model is not reinforced, tensile stresses due to eccentricity of axial forces, ductility, compression strength and the dynamic of the seismic forces must be analyzed for the right selection of the bricks, which finally enables to quantify the materials, necessary for the environmental analysis. The structural analysis is conducted according EC6 and EC8, as mentioned before, and the results reveal that the building in masonry can be constructed in three floors and that the building could structurally benefit, if wide thermal bricks with minimum compressive strength of $10 \mathrm{MPa}$ are used for the exterior walls and high resistant bricks (45 MPa), such as clinker bricks, for the structural inner walls. This configuration raises the stiffness and balances more evenly the slabs. This safety precaution causes another environmental disadvantage. Like the thermal bricks, the clinker bricks are heavy and manufactured under high temperature. This means more embodied energy and gas emissions, but concerning other properties the chosen bricks are favorable, as they have high thermal performances, acoustic insulation, moisture transfers and fire resistance.

The general characteristics of the masonry model

Number of floors: 3 , maximum height of the building $9.50 \mathrm{~m}$ Flat roof

Usage: Residential or office

Location: Seismic zone Slabs

Version 1: massive concrete with $20 \mathrm{~cm}$ height

Version 2: pre-fabricated concrete beams and ceramic blocks 40x16x25 cm, $20 \mathrm{~cm}$ height and specific weight: $8,2 \mathrm{kN} / \mathrm{m} 3$

General characteristics of walls

Thickness:

Exterior wall $290 \mathrm{~mm}$, thermal brick; thermal conductivity: $0,27 \mathrm{~W} / \mathrm{mK}$

Interior wall $115 \mathrm{~mm}$, clinker brick

Compressive strength of the thermal brick: $\mathrm{fb}=10 \mathrm{~N} / \mathrm{mm} 2$

Compressive strength of the clinker brick: $\quad \mathrm{fb}=45 \mathrm{~N} / \mathrm{mm} 2$

Specific weight of the thermal brick: $\quad \rho=18 \mathrm{kN} / \mathrm{m} 3$

Specific weight of the clinker brick: $\quad \rho=13 \mathrm{kN} / \mathrm{m} 3$

Mortar: M7,5 (fm = 7,5 N/mm2)

\section{III.THE BUILDING MODEL IN CONCRETE CONSTRUCTION}

The design of the reinforced Concrete Model follows the lines of the previous analysis. The exterior walls are built using thermal bricks of the same width and heating insulation capacity to guarantee the same thermal comfort performance as in the masonry model, but on the contrary, as these bricks have no structural functions, conveniently they have lower compressive strength, about $3 \mathrm{MPa}$, and less density, about $860 \mathrm{~kg} / \mathrm{m} 3$ for the benefit of the environment. The slabs are of reinforced concrete, according to the usual construction method, with the same thickness of $20 \mathrm{~cm}$ to maintain the same structural and acoustics quality. The interior walls have in this model no structural function, because of the existing columns; conveniently again, they are built with simple bricks with the same width but minor density of $780 \mathrm{~kg} / \mathrm{m} 3$. Principally the main differences to the masonry model are the columns and beams of reinforced concrete and the less density of the bricks. The structural analysis is conducted by one of the common software designated for concrete design according to the mentioned standards. The results confirm the same minimum stability as given in the masonry model. The beams are dimensioned with minimum possible height of $40 \mathrm{~cm}$, but for technical reasons to maintain the model as simple and economical as possible the columns dimensions are a little overdesigned with $30 \times 30 \mathrm{~cm}$ to align with the exterior walls and the beams.

\section{THE ENVIRONMENTAL DATA}

The environmental analysis is based on verification of embodied energy and the amount of carbon dioxide emitted through fabrication and transportation of the construction materials to the construction site. Other gas emissions due to less relevance are not considered. For this purpose the environmental benchmarks of the construction materials are needed and the quantity of the materials used. The data used for the ceramic blocks are collected from specifications released by manufacturers (M) [6], which use advanced technology in production, reducing gas emissions and energy consumption. Other documents as

- "INVENTORY OF CARBON AND ENERGY" [7], University of Bath (UB) of 2011,

$\begin{array}{cccc}- & \text { "DADOS } & \text { DE } & \text { REFERÊNCIA PARA } \\ \text { BENCHMARKING" } & {[8],} & \text { Reference Data for }\end{array}$
Benchmarking, of Centro Tecnológico da Cerâmica e do Vidro (CTCV), Technological Centre for Ceramics and Glass, of 2004, $\square$ “GUÍA DE L’EDIFICACIÓN SOSTENIBLE" [9]

- Guide for Sustainable Building of Institut Cerdà (IC) in Spain,

- "ECOLOGIA DOS MATERIAIS DE CONSTRUÇÃO" [10] Ecology of Construction Materials, a publication of the University of Minho (UM) in Portugal give insight to the environmental data of construction materials as required. The institutions and authors, referred above, present the data according to the type of energy used in production, including electric and thermal energy, and depending on the size of the plant, small, medium and large. In general the statistics and results are based on the use of thermal energy, since the electric power has a minor contribution of approximately $20 \%$. The values used in this context are averaged mixed values to increase the likelihood of a fair comparison of the data.

TABLE I

COMPARISON OF EMBODIED ENERGY AND CO2 EMISSIONS IN THE

\begin{tabular}{|l|c|c|c|c|c|}
\hline & UB & CTCV & M & IC & UM \\
\hline Embodied Energy $(\mathrm{MJ} / \mathrm{kg})$ & 3,0 & 1,37 & 1,02 & 4,5 & 2,99 \\
\hline $\mathrm{CO}_{2}$ Emissions $\left(\mathrm{kgCO}_{2} / \mathrm{kg}\right)$ & 0,23 & 0,112 & 0,10 & - & 0,19 \\
\hline
\end{tabular}

In Table 1 it is notable that the data of CTCV are significantly lower compared to the data of UB, IC and UM. The reason lies in the period of the data analysis. The other institutions analyzed data from plants over a period of 
several years, beginning in 1995, however these data, which are average values also reflect the years in which the industry had not yet taken steps to reduce energy and pollution in production. Unlike, the CTCV refers to the years 2004 forward, where the industry had already applied new manufacturing technologies to reduce energy consumption and pollution, but their data represent a national average value. The data of the manufacturers already incorporate advanced technologies and are more specific. In the Kyoto Protocol, industrialized countries agreed to a reduction of $25-40 \%$ of emissions by 2020 . So, since this research also analyses possible future developments, it is inclined to use the data of the manufacturers. Another very important reason for this decision is the climate of southern European regions. Bricks are not confronted with ice melting and therefore the

TABLE II

COMPARISON OF EMBODIED ENERGY AND CO2 EMISSIONS IN THE PRODUCTION OF CEMENT

\begin{tabular}{|c|c|c|c|c|}
\hline & UB & CIMPOR & IC & UM \\
\hline Embodied Energy (MJ/kg) & 4,6 & 3,591 & 7,02 & 4,00 \\
\hline $\mathrm{CO}_{2}$ Emissions $\left(\mathrm{kgCO}_{2} / \mathrm{kg}\right)$ & 0,83 & 0.676 & - & - \\
\hline
\end{tabular}

fabrication needs less backing. Same sources are used for data related to reinforced concrete and cement with the exception of data for cement. The international manufacturer CIMPOR is the largest producer of cement in Portugal. They provide in their annual report "RELATÓRIO DE SUSTENTABILIDADE 2011" [11], Sustainability Report 2011, the data related to the production of cement in 2011.

With the same logic as above the data of CIMPOR Portugal in Table 2 are more reliable and accurate for this research, since they represent the embodied energy and the actual pollution. Cement constitutes about $14 \%$ of the concrete, water (with water-to-cement ratio of 0.5 ) between 6 and $7 \%$ and the remaining $80 \%$ are filled with aggregates. It can be concluded that, proportionally, the $\mathrm{CO} 2$ emissions in a concrete plant are $0,10 \mathrm{kgCO} 2 / \mathrm{kg}$, with 0,095 for the cement $(14 \%)$ and $0,005(80 \%)$ for the aggregates, whereas the contribution of water is negligible. The $\mathrm{CO} 2$ emissions in the aggregate production are resulting from grinding the aggregates by using thermal energy, than the mixing in the concrete plant is done by electricity. The value of $\mathrm{CO} 2$ emission in aggregate production of the ICE document is confirmable; since the process is everywhere the same and the technology have not changed very much. The pollution in this process, in spite the dust produced, is low. Similarly, one can determine the values for the energy consumption involved in the production of concrete. The value assigned to the concrete is $0.81 \mathrm{MJ} / \mathrm{kg}$, with 0.504 and 0.307 for the cement and the aggregates. These values appear in the survey $(\mathrm{S})$ of the following table.

TABLE III

COMPARISON OF EMBODIED ENERGY AND CO2 EMISSIONS IN THE PRODUCTION OF CONCRETE

\begin{tabular}{|l|c|c|c|c|}
\hline & UB & S & IC & UM \\
\hline Embodied Energy $(\mathrm{MJ} / \mathrm{kg})$ & 0,95 & 0,81 & 1,008 & 1,00 \\
\hline $\mathrm{CO}_{2}$ Emissions $(\mathrm{kgCO} / \mathrm{kg})$ & 0,13 & 0,10 & - & 0,065 \\
\hline
\end{tabular}

The collection of data on steel production, particularly the rods used in reinforced concrete, and the analysis of the data about the embodied energy and emissions of $\mathrm{CO} 2$, becomes difficult and complex. The steel industry has a high emission of $\mathrm{CO} 2$ and being aware of this responsibility several research projects are running in Europe to develop technology aimed to reduce the emission of $\mathrm{CO} 2$ in the manufacturing as well as to store $\mathrm{CO} 2$ for use of production of electricity. The best-known project is ULCOS (UltraLight CO2 Steel Manufacturing). ULCOS is a consortium involving industry and their trade associations and the European Union. The project has entered its second phase in 2010 (ULCOS II) and its main aim is to reduce emissions $\mathrm{CO} 2$ to half. Similarly there has been a significant development in reducing pollution over the past 15 years, with recourse to the use of the electric furnace. At this time the industry is still far from the desired target. Another problem is the complexity of the manufacture of steel and the different production methods. In addition to this fact some data refer to the crude steel and other to treated steel, ready for use in construction. Furthermore it must be distinguished between data of virgin or recycled steel. One more reason to establish average values is the fact that it is practically impossible to have the accurate figures, because each order may come from a different source or plant and it is almost impossible to define rigorously the embodied energy and the $\mathrm{CO} 2$ emissions of the steel supplied. Rods are traded between steel mills for treatment, which makes it impossible to track and calculate the energy consumed and $\mathrm{CO} 2$ emitted by transportation. Generally it should be considered that in average the rods are made of recycled and virgin steel. Nevertheless, two documents "Energy Management" (SI) [12], and "Insights from Steel Benchmarks and the Environment" (TK) [13], although not complete, but confirm the information contained in the ICE document.

TABLE IV

COMPARISON OF EMBODIED ENERGY AND CO2 EMISSIONS IN THE PRODUCTION OF STEEL

\begin{tabular}{|l|c|c|c|c|c|c|}
\hline & \multicolumn{3}{c|}{ UB } & SI & TK & UM \\
\cline { 2 - 7 } & Virgin & Recycled & Medium & Crude & Virgin & Virgin \\
\hline Embodied Energy $(\mathrm{MJ} / \mathrm{kg})$ & 29,20 & 8,8 & 17,4 & 18,4 & - & 10 \\
\hline $\mathrm{CO}_{2}$ Emissions $\left(\mathrm{kgCO}_{2} / \mathrm{kg}\right)$ & 2,77 & 0,45 & 1,40 & 1,36 & 2,0 & 0,557 \\
\hline
\end{tabular}

Considering the data in Table 4 and the facts mentioned above, the average values for rods in the ICE document reflect more the reality and are more suitable for this analysis. Thus, the medium value constitutes of $59 \%$ recycled steel (normal for the production of rods in Europe; in the rest of the world the percentage may vary between 35.5 and 39\%) and the rest of virgin steel [3] with proportional energy consumption of $17.40 \mathrm{MJ} / \mathrm{kg}$, and the pollution created by $\mathrm{CO} 2$ of $1,40 \mathrm{kgCO} 2 / \mathrm{kg}$. Resuming the chosen construction materials, the following values for the quantification of embodied energy and carbon dioxide emissions are used for both constructive solutions.

TABLE V

RECOMMENDED AVERAGE CO2 EMISSIONS AND EMBODIED ENERGY EE VALUES FOR THE SELECTED CONSTRUCTION MATERIALS

\begin{tabular}{|l|c|c|}
\hline \multicolumn{1}{|c|}{ Construction material } & $\mathrm{CO}_{2}\left(\mathrm{kgCO}_{2} / \mathrm{kg}\right)$ & $\mathrm{EE}(\mathrm{MJ} / \mathrm{kg})$ \\
\hline Ceramic brick & 0,100 & 1,02 \\
\hline Concrete & 0,100 & 0,81 \\
\hline Steel & 1,400 & 17,40 \\
\hline $\begin{array}{l}\text { Mortar with a compressive } \\
\text { strength of 5 - } 10 \mathrm{MPa}\end{array}$ & 0,213 & 1,40 \\
\hline
\end{tabular}

These data refer to the manufacturing and delivery of the construction materials at factory gate. $\mathrm{CO} 2$ emissions and embodied energy of transporting of the materials from factory gate to construction site must additionally be calculated. The document "CODE FOR SUSTAINABLE HOMES" [14] provides the data for the quantification of 
$\mathrm{CO} 2$ emissions in transportation. Most of this type of transport is performed on road so either nationally or within the European Union. National regulations that apply in terms of type and measures of trucks that can transport the building materials are based on the regulations and directives of the European Union. The "International Road Transport Guide" of 2006 contains the general rules and in accordance with these directives transport can be calculate with articulated trucks with more than six axes and a freight limit of maximum 37 tons for Portugal and 36 tons for Spain. The manufacture of concrete can be made on site or by order. In the latter case the distance may not exceed 50 $\mathrm{km}$ to ensure reasonable pricing and avoid technical problems with the setting of the concrete. In Portugal, usually, a concrete plant is available within a convenient distance. Since the project is of small/medium size it is appropriate to order the concrete. For the transport of concrete a mobile truck mixer of 12 tons maximum capacity can be used, which corresponds with less capacity than 33 tons. According to the above mentioned document, $\mathrm{CO} 2$ emission in transport with trucks with less capacity than 33 tons are of $0,747 \mathrm{kgCO} 2 / \mathrm{km}$ and with trucks of superior capacity of $0,929 \mathrm{kgCO} 2 / \mathrm{km}$. Regarding the quantification of the embodied energy for transportation it has to be mentioned that the ratio of energy consumption in transport in relation to the production of the transported material, expressed in percentage, would be equal in both constructive solutions. The transportation is generally done by trucks, as the distances are small. The energy consumption per truck is $0.000402 \mathrm{MJ} /(\mathrm{kg} . \mathrm{km})$; a small value for the common distances up to $100 \mathrm{~km}$ as compared with the data of embodied energy, but not negligible.

\section{COMPARISON OF THE RESUltS}

For both constructive solutions, the building model is designed for a minimum usage of construction materials, assuring a fair comparison. A comparison of the quantities of construction materials used for the models shows the trend and the direction of this study, since the environmental assessment is dependent on the masses

TABLE VI COMPARISON OF MASSES IN KG, CM - MM VERSION 1

\begin{tabular}{l|r|r|r|r|}
\hline $\begin{array}{l}\text { Construction } \\
\text { Material }\end{array}$ & \multicolumn{1}{|c|}{ CM } & \multicolumn{1}{c|}{ MM } & \multicolumn{1}{c|}{$\begin{array}{l}\text { Difference } \\
\text { (CM-MM) }\end{array}$} & $\begin{array}{c}\text { Difference } \\
(\%)\end{array}$ \\
\hline Brick (exterior) & 99.849 & 219.866 & -120.037 & -120 \\
\hline Brick (interior) & 23.793 & 45.211 & -21.418 & -90 \\
\hline Concrete & 457.691 & 284.836 & +172.855 & +38 \\
\hline Steel, rods & 26.838 & 19.712 & +7.126 & +27 \\
\hline Mortar & 25.844 & 27.282 & -1.438 & -6 \\
\hline TOTAL & 634.015 & \multicolumn{1}{|c|}{596.907} & +37.108 & +6 \\
\hline
\end{tabular}

In the Masonry Model we identify a reduction of 172855 $\mathrm{kg}$ of concrete due to the lack of columns and bars. On the other hand we have a rise of 120037 and $21418 \mathrm{~kg}$ of bricks because of the more dense thermal brick and the clinker brick for the interior walls. Considering also the little differences of steel and mortar, in general the Masonry Model Version 1 uses $37108 \mathrm{~kg}$ less material for the structure, which is a very moderate reduction of the masses.
TABLE VII

COMPARISON OF MASSES IN KG, CM - MM VERSION 2

\begin{tabular}{|l|r|r|r|r|}
\hline $\begin{array}{l}\text { Construction } \\
\text { Material }\end{array}$ & \multicolumn{1}{c|}{ CM } & MM & $\begin{array}{c}\text { Difference } \\
\text { (CM-MM) }\end{array}$ & $\begin{array}{c}\text { Difference } \\
(\%)\end{array}$ \\
\hline Brick (exterior) & 219.866 & 219.866 & -120.037 & -120 \\
\hline Brick (interior) & 23.793 & 45.211 & -21.418 & -90 \\
\hline Ceiling brick & 0 & 48.871 & -48.871 & - \\
\hline Concrete & 457.691 & 145.350 & +312.341 & +68 \\
\hline Steel, rods & 26.838 & 6.762 & +20.076 & +75 \\
\hline Mortar & 25.844 & 27.282 & -1.438 & $-5,6$ \\
\hline TOTAL & 634.015 & 493.342 & +140.673 & +22 \\
\hline
\end{tabular}

In case of Masonry Model Version 2 the reduction of concrete with $312341 \mathrm{~kg}$ is much more notable due to additional lack of concrete slabs compared with Masonry Model Version 1. The brick ceiling, composed of bricks, cement and rods, is much lighter as concrete slab and substitutes the slab of Version 1 with only $48871 \mathrm{~kg}$. Consequently the total reduction of materials in Version 2 is $140673 \mathrm{~kg}$ compared to the Concrete Model. Comparing both Versions 1 and 2 of the Masonry Model, it can be verified that Version 2 reduces the total weight $17,35 \%$, specifically $49 \%$ in concrete and $65,7 \%$ in steel, Table 8 .

TABLE VIII

COMPARISON OF MASSES IN KG, MM VERSION 1 - MM VERSION 2

\begin{tabular}{|c|c|c|c|c|}
\hline $\begin{array}{l}\text { Construction } \\
\text { Material }\end{array}$ & MM1 & MM2 & $\begin{array}{c}\text { Difference } \\
\text { (MM1-MM2) }\end{array}$ & $\begin{array}{c}\text { Difference } \\
(\%)\end{array}$ \\
\hline Brick (exterior) & 219.866 & 219.866 & -120.037 & 0 \\
\hline Brick (interior) & 45.211 & 45.211 & -21.418 & 0 \\
\hline Ceiling brick & 0 & 48.871 & -48.871 & - \\
\hline Concrete & 284.836 & 145.350 & +139.486 & +49 \\
\hline Steel, rods & 19.712 & 6.762 & +12.950 & $+65,7$ \\
\hline Mortar & 27.282 & 27.282 & -1.438 & 0 \\
\hline TOTAL & 596.907 & 493.342 & +103.565 & $+17,35$ \\
\hline
\end{tabular}

The same way the Concrete Model is compared in both Versions.

TABLE IX

COMPARISON OF MASSES IN KG, CM VERSION 1 - CM VERSION 2

\begin{tabular}{|l|r|r|r|r|}
\hline $\begin{array}{l}\text { Construction } \\
\text { Material }\end{array}$ & \multicolumn{1}{c|}{ CM1 } & \multicolumn{1}{c|}{ CM2 } & $\begin{array}{c}\text { Difference } \\
\text { (CM1-CM2) }\end{array}$ & $\begin{array}{c}\text { Difference } \\
(\%)\end{array}$ \\
\hline Brick (exterior) & 99.849 & 99.849 & 0 & 0 \\
\hline Brick (interior) & 23.793 & 23.793 & 0 & - \\
\hline Ceiling brick & 0 & 48.871 & -48.871 & $+30,5$ \\
\hline Concrete & 457.691 & 318.205 & +139.486 & $+48,25$ \\
\hline Steel, rods & 26.838 & 13.888 & +12.950 & 0 \\
\hline Mortar & 25.844 & 25.844 & 0 & $+16,3$ \\
\hline TOTAL & 634.015 & 530.450 & +103.565 & \\
\hline
\end{tabular}

The Concrete Model in Version 2 is in total 16,3\% lighter, specifically $30,5 \%$ in concrete and $48,25 \%$ in steel, Table 9. As the Concrete Model in Version 2 according to the differences in percentage and the proportionality lies in between the Versions MM1 and MM2, no further attention is paid to avoid confusion and focusing more on the extreme values of CM1 and MM2.

TABLE $X$

COMPARISON OF CO2 EMISSIONS (KGCO2), THE PERCENTAGE OF EMISSIONS

\begin{tabular}{|l|r|r|r|r|r|r|}
\hline \multicolumn{2}{c|}{} & \multicolumn{2}{c|}{ PER MATERIAL } & \multicolumn{2}{c|}{ MM Version 1 } & \multicolumn{2}{c|}{ MM Version 2 } \\
\cline { 2 - 7 } $\begin{array}{l}\mathrm{CO}_{2} \text { emissions } \\
\text { according to table 5 }\end{array}$ & \multicolumn{1}{c|}{$\mathrm{P}$} & \multicolumn{1}{c|}{$\%$} & $\mathrm{P}$ & \multicolumn{1}{c|}{$\%$} & \multicolumn{1}{c|}{$\mathrm{P}$} & \multicolumn{1}{c|}{$\%$} \\
\hline Concrete & 45.769 & 45,2 & 28.484 & 32,2 & 14.535 & 23,7 \\
\hline Brick & 12.364 & 12,2 & 26.508 & 30 & 31.395 & 51,3 \\
\hline Mortar & 5.505 & 5,5 & 5.811 & 6,6 & 5.811 & 9,5 \\
\hline Steel, rods & 37.573 & 37,1 & 27.597 & 31,2 & 9.467 & 15,5 \\
\hline Total at fabric gate & 101.211 & 100,0 & 88.399 & 100,0 & 61.208 & 100,0 \\
\hline Transport & 5.577 & 5,2 & 5950 & 6,3 & 4.044 & 6,2 \\
\hline TOTAL & 106.788 & & 94.349 & & 65.251 & \\
\hline
\end{tabular}

P: Production 
Tables 10 and 11 show that in case of the concrete construction the primary materials, concrete and steel, contribute with a majority of $45 \%$ and $37 \%$ of $\mathrm{CO} 2$ emissions of all materials used for the construction, and respectively with $37 \%$ and $47 \%$ of embodied energy. In version 2 of the Masonry Model, the main materials brick and concrete contribute with 51 and $24 \%$ in $\mathrm{CO} 2$ emissions, and $54 \%$ and $20 \%$ in embodied energy. The largest consumer of energy and emitter of $\mathrm{CO} 2$, steel, has a far less significant contribution in this version, therefore the total $\mathrm{CO} 2$ emissions with $65251 \mathrm{kgCO} 2$ are $39 \%$ lower and the embodied energy with $609982 \mathrm{MJ}$ is $41 \%$ lower than in case of concrete construction. In this version the use of steel is significantly reduced while the brick ceiling uses much less steel, on the contrary, in Version 1 with solid slabs, the use of steel rods is very high. In the first version of the Masonry.

TABLE XI

COMPARISON OF EMBODIED ENERGY (MJ), PERCENTAGE OF ENERGY CONSUMPTION PER MATERIAL

\begin{tabular}{|l|r|r|r|r|r|r|}
\hline \multirow{2}{*}{$\begin{array}{l}\text { Embodied Energy } \\
\text { according to table 5 }\end{array}$} & \multicolumn{2}{|c|}{ CM } & \multicolumn{2}{c|}{ MM Version 1 } & \multicolumn{2}{c|}{ MM Version 2 } \\
\cline { 2 - 7 } & \multicolumn{1}{c|}{$\%$} & \multicolumn{1}{c|}{$\mathrm{P}$} & \multicolumn{1}{c|}{$\%$} & \multicolumn{1}{c|}{$\mathrm{P}$} & \multicolumn{1}{c|}{$\%$} \\
\hline Concrete & 370.730 & 37,1 & 230.717 & 28,32 & 117.734 & 19,83 \\
\hline Ceramic Brick & 126.114 & 12,6 & 270.379 & 19,05 & 320.227 & 53,93 \\
\hline Mortar & 36.182 & 3,6 & 38.195 & 3,84 & 38.195 & 6,43 \\
\hline Steel, rods & 466.981 & 46,7 & 342.989 & 48.79 & 117.659 & 19,81 \\
\hline Total at fabric gate & 1.000 .007 & 100,0 & 882.279 & 100,00 & 593.815 & 100,00 \\
\hline Transport & 27.989 & 2,7 & 23.851 & 2,32 & 16.168 & 2,65 \\
\hline TOTAL & 1.027 .996 & & 906.131 & & 609.982 & \\
\hline
\end{tabular}

Model, although it fosters an improvement, due to the absence of columns, compared with concrete construction, the contributions of $\mathrm{CO} 2$ emissions and energy consumption remain high. Thus, the second version of structural masonry becomes more environmentally favorable, as can be seen from the total values Table 12 shows the values of embodied energy and $\mathrm{CO} 2$ emission per square meter of construction for all three options studied. As could be verified in the calculations before, the reductions in the Masonry Model Version 1 are very low compared to the Concrete Construction Model. One reason is the fact that the reduction of masses in Version 1 is low. The second reason is the fact that the carbon dioxide emission of brick is equal to concrete and that the embodied energy is even higher. The production of bricks consumes a lot of energy for backing and causes also the high emissions. This can be considered another weakness of bricks beside the structural.

\section{TABLE XII}

COMPARISON OF EMBODIED ENERGY AND CO2 EMISSION PER M2 OF

\begin{tabular}{|l|c|c|c|}
\hline & $\mathrm{CM}$ & MM Version 1 & MM Version 2 \\
\hline Embodied Energy $\left(\mathrm{MJ} / \mathrm{m}^{2}\right)$ & 2044 & 1801 & 1213 \\
\hline $\mathrm{CO}_{2}$ Emissions $\left(\mathrm{kgCO}_{2} / \mathrm{m}^{2}\right)$ & 212 & 188 & 130 \\
\hline
\end{tabular}

The expressions of the environmental benchmarks in square meter, as shown in table 10, emphasize the differences between the models. The Masonry Model in Version 2 with brick ceilings consumes less energy, 1213 $\mathrm{MJ} / \mathrm{m} 2$, as the Masonry Model Version 1 with concrete slabs, $1801 \mathrm{MJ} / \mathrm{m} 2$, and the Model in concrete consumes the most with $2044 \mathrm{MJ} / \mathrm{m} 2$. The same pattern can be seen concerning the $\mathrm{CO} 2$ emission. The differences are mainly related to the quantity of steel used for the different models. As shown in tables 6 and 7 the quantity of steel reduces from the Concrete Model to the Masonry Model Version 1 and even more significantly in the Masonry Model Version 2 as already mentioned in the sections before.

\section{CONCLUSION}

This research compares the $\mathrm{CO} 2$ emissions and the Embodied Energy of construction materials necessary for the construction of two equal building models constructed with reinforced concrete and bricks and the other in two versions, one in unreinforced masonry with concrete slabs and than in unreinforced masonry with prefabricated beams and ceramic blocks. To enable an environmental comparison, the models are designed physically identical, considering three conditions. First, each model is designed with the minimum necessary structure to limit the quantity of construction material. Second, all models are designed to have fairly similar thermal comfort to guarantee the same quality for occupiers. Construction materials for the partitions, doors and windows are excluded for the comparison, as they are equal for the models. Under these conditions the benchmarks obtained show that in small housings with spans up to $7 \mathrm{~m}$, concrete structures can be avoided, even in seismic zones, using masonry construction with prefabricated beams and ceramic blocks for slabs, which significantly contributes to environment. Considering the constructions materials, only the Masonry Model with prefabricated beams and ceramic blocs for slabs emits $39 \%$ less CO2 and embodies $41 \%$ less energy than the Concrete Model with concrete slabs. Concerning energy consumption during life cycle, it will be additionally less $7,46 \%$, when the energy for heating, for a service life of 50 years, is taken into account. It becomes clear that these reductions are due to the less use of steel in the Masonry Models and it is not due to the ceramic brick. This conclusion is so far limited to southern European regions, as the data used are from this zone. However, similar estimation can be applied to other countries or regions with similar climate conditions and technological progress, especially in the brick manufacturing, assuming that the more recent production technologies with less energy consumption are applied. On the other hand, for regions with cold climate it can be considered that the ceramic material needs more backing and consequently the embodied energy and gas emissions are higher, but where earthquake is not an issue lighter ceramic bricks instead of the clinker bricks in the interior can be used for masonry construction. The methodology used and the main results are of general interest, even if some of specific values may be different according to regional conditions.

\section{ACKNOWLEDGMENT}

This research is a result of a doctorate research entitled Sustainable Analysis of Structural Masonry. The Center for Investigation of Architecture, Urbanism and Design, CIAUD, of the Faculty of Architecture of the University of Lisbon supported this undertaking and helped with all means.

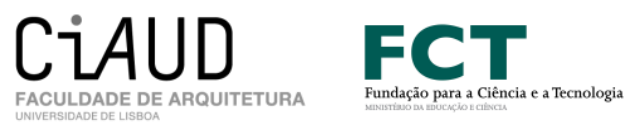




\section{REFERENCES}

[1] J. C. Salcido, A. A. Raheem, Srinivasan Ravi, Comparison of embodied energy and environmental impact of alternative materials used in reticulated dome construction, Building and Environment, Elsevier, Volume 96, 1 February 2016, Pages 22-34, (2016)

[2] S. Mishra, J. A. Usmani, Comparison of embodied energy in different masonry materials, Mishra et al., International Journal of Advanced Engineering Technology E-ISSN 09763945, New Delhi, India, (2013)

[3] N. Yokoo, T. Oka, K. Yokoyama, T. Sawachi and M. Yamamoto, Comparison of Embodied Energy/CO2 of Office Buildings in China and Japan, Journal of Civil Engineering and Architecture 9, 300-307 D doi: 10.17265/1934-7359/2015.03.008, DAVID PUBLISHING, (2015)

[4] L.R. Manjunatha, S.R. Anvekar, S.S. Sagari, K. Archana, An Economic and Embodied Energy Comparison of Geo-polymer, Blended Cement and Traditional Concretes, Journal of Civil Engineering Technology and Research-Volume 2 Issue 1,Jan-June 2014, ISSN 2349-9575, At Bengaluru, Volume 2, (2014)

[5] S. Sazedj, Análise de Sustentabilidade de Alvenaria Estrutural, Sustainability analysis of structural masonry, Ph.D theses, Faculty of Architecture, Technical University of Lisbon, (2012)

[6] Grupo Preceram, Pombal, Portugal, http://www.preceram.pt , (2010) Tabicesa S.A.U., Valdivia, Spain, http://www.tabicesa.es , (2010)

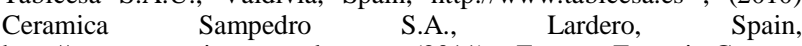
http://www.ceramicasampedro.com, (2011) Fornace Eugenio Casetta, Alba, Italy, http://www.fornacecasetta.it, (2013) Latersud srl Industria Laterizi, Taurianova, Italy, http://www.latersud.it, (2013)

[7] G. Hammond e C. Jones, Inventory of Carbon and Energy (ICE), Department of Mechanical Engineering, University of Bath (UB), Bath, (2011)

[8] Centro Tecnológico da Cerâmica e do Vidro (CTCV), Reference Data for Benchmarking, Coimbra, (2004)

[9] F. Rovira, L. Josep e M. Casado, Institut Cerdà (IC), Guía de l'edificación sostentible, Barcelona, (1999)

[10] S. Jalali, F. E. Marcelo e J.A. Nelson, Ecologia dos Materiais de Construção, B. Berge, 1999, translated and adapted for Portuguese, Universidade Minho (UM), Guimarães, 2007

[11] CIMPOR, Cimentos de Portugal, SGPS, SA., Relatório de Sustentabilidade 2011, Lisboa, (2011)

[12] Stahlinstitut VDEh und Wirtschaftsvereinigung Stahl im StahlZentrum, Energy Managemente, http://www.stahlonline.de/Deutsch/Linke_Navigation/Technik_Forsc hung/Energie_und_Umwelttechnik/E

nergiewirtschaft.php?highmain $=2$ \&highsub $=3$ \&highsubsub $=1$, Düsseldorf, 2010, (last access May 2011)

[13] H.J. Weddige, Thyssen Krupp Steel, Insights from steel - Benchmarks and the environmente, Essen, (2009)

[14] Department for Communities and Local Government, UK, Code for Sustainable Homes, Technical Guide, Version 2, London, (Maio 2009) 